\title{
The Crystal and Molecular Structure of Cyano(methyliso- cyanide)gold(I)
}

\author{
STEINAR ESPERÅS
}

Department of Chemistry, University of Bergen, N-5014 Bergen-Univ., Norway

The crystal and molecular structure of cyano(methylisocyanide)gold(I), $\mathrm{AuCN}\left(\mathrm{CNCH}_{3}\right)$, has been determined by three-dimensional X-ray methods. The crystals are orthorhombic, $\mathrm{Pbcm}$, unit cell $a=10.989(6) \AA, \quad b=6.899(6) \quad \AA$, $c=6.359(5) \AA, Z=4$. The structure analysis is based on 325 intensities collected on a Syntex $P 2_{1}$ diffractometer using MoK $\alpha$ radiation. Patterson and Fourier syntheses were used to solve the structure, and full-matrix least squares refinement gave an $R$-value of 0.068 .

The gold atom is almost linearly coordinated, the $\mathrm{C}-\mathrm{Au}-\mathrm{C}$ angle being $176(2)^{\circ}$ and the $\mathrm{Au}-\mathrm{C}$ (CN) and $\mathrm{Au}-\mathrm{C}\left(\mathrm{CNCH}_{3}\right)$ distances $2.01(5)$ and $1.98(5) \AA$, respectively. The molecules, except for the hydrogen atoms, are situated on crystallographic mirror planes. The structure is built up from monomeric units linked together in two-dimensional polymeric layers parallel to the $b c$-plane, through very weak metal-metal interactions.

Univalent gold is mainly found to have a linear coordination, even when the analogous copper and silver complexes show a tetrahedral geometry. 1 Most of the $\mathrm{Au}(\mathrm{I})$ compounds like the majority of the $\mathrm{Ag}(\mathrm{I})$ and $\mathrm{Cu}(\mathrm{I})$ compounds appear to be appreciably covalent. The univalent coinage metal complexes often occur as polymers, (discrete low polymers, infinite polymers or metal atom cluster compounds) either with bridging groups connecting the metal atoms or with weak metal-metal interactions. ${ }^{2}$ Few crystal structures of univalent gold compounds have been determined, and the only X-ray work done on isocyanide complexes of coinage metals $(\mathrm{I})$ is on $\mathrm{CuI}\left(\mathrm{CNCH}_{3}\right)$, a complex with relatively short $\mathrm{Cu} \cdots \mathrm{Cu}$ distances. ${ }^{3}$ As the present gold(I) complex was insoluble in water and all the usual organic solvents, some kind of polymeric arrangement was also expected to be found here.

\section{EXPERIMENTAL}

The crystals were prepared by a reaction between methyl iodide and tetraphenylarsonium dicyanoaurate $(\mathrm{I}) .^{4}$

$$
\mathrm{CH}_{3} \mathrm{I}+\mathrm{Au}(\mathrm{CN})_{2}-\frac{14 \mathrm{~d}}{\text { room temp. }} \rightarrow \mathrm{AuCN}\left(\mathrm{CNCH}_{3}\right)
$$

The crystalline product was obtained as colourless plates elongated along the $c$ axis. Data were collected with a Syntex $P 2_{1}$ fourcircle diffractometer in the $\theta-2 \theta$ mode with graphite monochromator. Accurate cell constants were obtained by means of least squares calculations based on the reflecting positions of 15 high angle reflections. The cell data are $a=10.989(6) \AA, b=6.899(6) \AA, c=6.359(5) \AA$, $Z=4$ and $d \mathrm{c}=3.64 \mathrm{~g} \mathrm{~cm}^{-3}$. The systematic absences are $0 k l$ for $k=2 n+1$ and $h 0 l$ for $l=2 n+1$ in the orthorhombic crystal system. The space group is Pbem (No. 57) as the alternative group, $P c a 2_{1}$, was discarded during the structure determination.

The data were collected with MoK $\alpha$ radiation. Within $\angle \theta=25^{\circ}, 325$ reflections were found to have intensities stronger than three times the standard deviations. Variable scan rates, between 1.5 and $29.3^{\circ} / \mathrm{min}$ in $2 \theta$, depending on the intensity of a pre-scan, were used. Three standard reflections were measured at intervals of 50 reflections. No decomposition of the crystal was observed during the data collection.

The data were corrected for Lorentz and polarization effects. Absorption correction, calculated by the analytical method with program ABSCOR ${ }^{5}$ was also applied $\left(\mu=313 \mathrm{~cm}^{-1}\right)$. No extinction correction was found necessary. 


\section{STRUCTURE ANALYSIS}

Of the two possible space groups, $\mathrm{Pbcm}$ and $P c a 2_{1}$, the centrosymmetric, $P b c m$, was the first choice. A three-dimensional Patterson map, calculated on basis of the 325 observed reflections, revealed the gold atoms in crystallographic mirror planes at $z=+1$. Consequently, all non-hydrogen atoms had to be located in these planes, and a Fourier synthesis confirmed this. Full-matrix least squares refinement with anisotropic temperature factors for the gold atom and isotropic temperature factors for the lighter atoms (hydrogen not included) gave a final value of the reliability index, $R=\sum|| F_{\mathrm{o}}|-| F_{\mathrm{c}}|| / \sum\left|\boldsymbol{F}_{\mathrm{o}}\right|$, of $\mathbf{0 . 0 6 8}$. There was, however, a possibility that the complex was $\mathrm{NC}-\mathrm{Au}-\mathrm{NC}-\mathrm{CH}_{3}$, i.e. a methylcyanide instead of a methylisocyanide. A parallel refine. ment based on the $\mathrm{N}$-bonded complex yielded a slightly higher $R$-value $(0.069)$ and rather unreasonable temperature factors.

Attempts to refine the structure in the non. centric space group were not successful.

A final difference electron density map showed several large peaks near the gold position, the highest of these was $2.6 \mathrm{e} / \AA^{3}$. No peaks above $1.0 \mathrm{e} / \AA^{3}$ appeared elsewhere in the map.

The atomic scattering factor curves used were taken from the International Tables. ${ }^{\circ}$ Those for the gold atom were corrected for anomalous dispersion, using $\Delta f^{\prime}$ and $\Delta f^{\prime \prime}$ values calculated by Cromer, ${ }^{7}$ and letting $f$ equal the magnitude of the complex scattering factor.

Observed and calculated structure factors following the last refinement cycle can be obtained from the author, upon request.

All calculations were carried out on an ICL 4130 computer at the University of Warwick, England. Apart from the local initial data processing program and ABSCOR (a local version), all programs were made by Dr. D. R. Russel, University of Leicester.

\section{RESULTS AND DISCUSSION}

The final positional and thermal parameters are listed in Tables 1 and 2. Interatomic distances and angles are listed in Table 3. Bond lengths and bond angles with atomic numbering in the cyano(methylisocyanide)gold(I) molecule are shown in Fig. 1, and a stereoscopic drawing
Table 1. Final atomic coordinates in fractions of cell edges with standard deviations in parentheses.

\begin{tabular}{llll}
\hline & $x$ & $y$ & $z$ \\
\hline Au & $0.4672(1)$ & $0.1095(2)$ & 0.25 \\
C1 & $0.285(4)$ & $0.097(7)$ & 0.25 \\
C2 & $0.647(4)$ & $0.103(7)$ & 0.25 \\
C3 & $0.890(6)$ & $0.083(9)$ & 0.25 \\
N1 & $0.180(3)$ & $0.078(5)$ & 0.25 \\
N2 & $0.755(4)$ & $0.102(6)$ & 0.25 \\
\hline
\end{tabular}

Table 2. Atomic thermal parameters $\left(\times 10^{2}\right)$ with standard deviations in parentheses. For $\mathrm{Au}$ the expression is exp $\left[-\frac{1}{2}\left(h^{2} a^{-2} B_{11}+k^{2} b^{-2}\right.\right.$. $B_{22}+l^{2} c^{-2} B_{33}+2 h k a^{-1} b^{-1} B_{12}+2 h l a^{-1} c^{-1} B_{13}+$ $\left.\left.+2 k l b^{-1} c^{-1} B_{28}\right)\right]$ and for $\mathrm{C}$ and $\mathrm{N}$ the expression is $\exp \left(-B \sin ^{2} \theta / \lambda^{2}\right)$.

\begin{tabular}{llcll}
$\mathrm{Au}$ & $251(8)$ & $319(9)$ & $622(11)$ & $\left(B_{11}, B_{22}, B_{33}\right)$ \\
& 0 & 0 & $-4(9)$ & $\left(B_{23}, B_{13}, B_{12}\right)$ \\
C1 & $404(86)$ & & & $(B)$ \\
C2 & $429(92)$ & & & \\
C3 & $697(149)$ & & & \\
N1 & $409(75)$ & & & \\
N2 & $505(89)$ & & \\
\hline
\end{tabular}

Table 3. Bond lengths $(\AA)$ and bond angles $\left({ }^{\circ}\right)$ in the cyano(methylisocyanide)gold(I) molecule. Standard deviations in parentheses.

\begin{tabular}{llll}
$\mathrm{Au}-\mathrm{C} 1$ & $2.01(4)$ & $\mathrm{C} 1-\mathrm{Au}-\mathrm{C} 2$ & $176(2)$ \\
$\mathrm{Au}-\mathrm{C} 2$ & $1.98(5)$ & $\mathrm{Au}-\mathrm{Cl}-\mathrm{N} 1$ & $175(4)$ \\
$\mathrm{Cl}-\mathrm{N1}$ & $1.15(6)$ & $\mathrm{Au}-\mathrm{C} 2-\mathrm{N} 2$ & $179(4)$ \\
$\mathrm{C} 2-\mathrm{N} 2$ & $1.18(6)$ & $\mathrm{C} 2-\mathrm{N} 2-\mathrm{C} 3$ & $175(5)$ \\
$\mathrm{N} 2-\mathrm{C} 3$ & $1.50(8)$ & & \\
\hline
\end{tabular}

showing the packing of molecules is given in Fig. 2.

The crystal structure consists of discrete $\mathrm{AuCN}\left(\mathrm{CNCH}_{8}\right)$ molecules. The gold atom is, as usual for $\mathrm{Au}(\mathrm{I})$, linearly coordinated with a $\mathrm{C}-\mathrm{Au}-\mathrm{C}$ angle of $176(2)^{\circ}$. Each gold atom is, however, in addition to the two carbon ligand atoms, surrounded by six more distant gold atoms, situated approximately at the corners of a regular hexagon. The $\mathrm{Au}-\mathrm{Au}$ distances are 3.524(4), 3.593(3), and 3.724(3) A. Thus the metal atoms link the molecules weakly together into two-dimensional polymeric layers parallel to the bc-plane.

Acta Chem. Scand. A 30 (1976) No. 7 


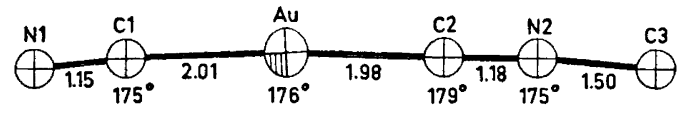

Fig. 1. The cyano(methylisocyanide)gold(I) molecule with bond lengths $(\AA)$ and bond angles $\left({ }^{\circ}\right)$ indicated.

In each layer the metal atoms form a central sheet surrounded on both sides by the ligands. There are no contacts shorter than the sum of van der Waals radii.

The molecular structure of $\mathrm{AuCN}\left(\mathrm{CNCH}_{3}\right)$ resembles those found for other univalent gold complexes, although the type of metal-metal interaction pattern found in the present investigation has not been found before. Several authors report polymeric structures of gold (I) compounds often with rather short $\mathrm{Au}-\mathrm{Au}$ distances..$^{1,8-12}$ It is, however, not clear when a metal-metal distance can be interpreted as corresponding to an interaction.

Whether the gold-gold separations of 3.52-3.72 $\AA$ in the complex reported here, AuCN $\left(\mathrm{CNCH}_{3}\right)$, represent weak bonding is difficult to decide. However, on the basis of the insolubility of the crystals in water as well as in all the usual organic solvents, ${ }^{4}$ this is possibly the case.

The linear coordination of the metal atom is common for univalent gold complexes. Copper(I) compounds on the other hand are

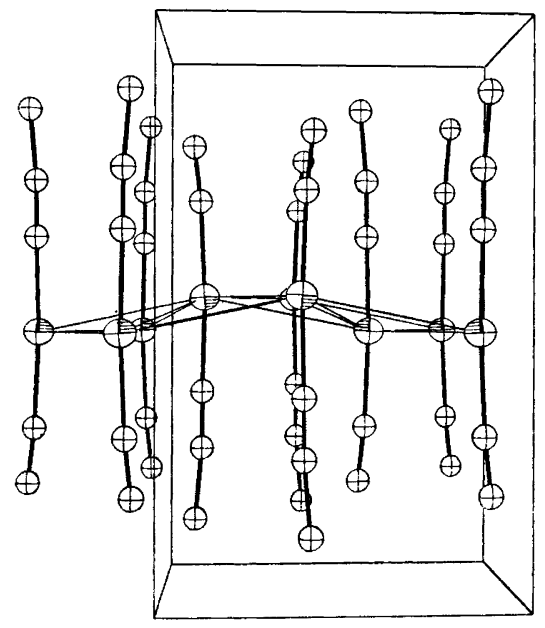

mostly found in a tetrahedral arrangement and quite rarely take part in linear coordination. Silver(I) complexes have a strong tendency to occur in both tetrahedral and linear coordination.

Dunitz and Orgel ${ }^{13}$ have suggested that the linear two-coordination of univalent gold is due to the formation of $s d$-hybrids on the central atom. Charlton and Nichols ${ }^{14}$ report, however, on basis of ${ }^{197} \mathrm{Au}$ Mössbauer spectroscopy on $\mathrm{Au}(\mathrm{I})$ complexes that the hybrids most likely contain a substantial degree of $p$-character. This view is supported by Machmer et al. ${ }^{15}$ who studied gold(I) chloride by NQR spectro. scopy.

The $\mathrm{Au}-\mathrm{C} \quad(\mathrm{CN})$ and $\mathrm{Au}-\mathrm{C} \quad\left(\mathrm{CNCH}_{3}\right)$ coordination distances are 2.01(5) and 1.98(5) $\AA$, respectively. They may be compared with the corresponding distances in $\mathrm{i}-\mathrm{C}_{3} \mathrm{H}_{7} \mathrm{NH}_{2} \mathrm{AuC} \equiv$ $\mathrm{CC}_{6} \mathrm{H}_{5}$ of $1.94 \AA^{8}$, in $\mathrm{PPh}_{3} \mathrm{AuC}_{6} \mathrm{~F}_{5}$ of $2.07 \AA,{ }^{16}$ and in $\mathrm{KAu}(\mathrm{CN})_{2}$ of $2.12 \AA^{10}$ and are in the expected range. Also the other bond lengths are normal. All the bond angles are approximately $180^{\circ}$ and thus the molecules are almost linear.

In the present complex the IR spectrum shows absorptions at $c a .2160$ and ca. $2290 \mathrm{~cm}^{-1}$, the first is assigned to the cyanide group, the latter to the isocyanide group. While $v_{\mathrm{CN}}(\mathrm{CN})$ is in the expected range, ${ }^{18} v_{\mathrm{CN}}(\mathrm{CNR})$ is about $120 \mathrm{~cm}^{-1}$ above the corresponding frequency in the free ligand.10 This increase indicates a

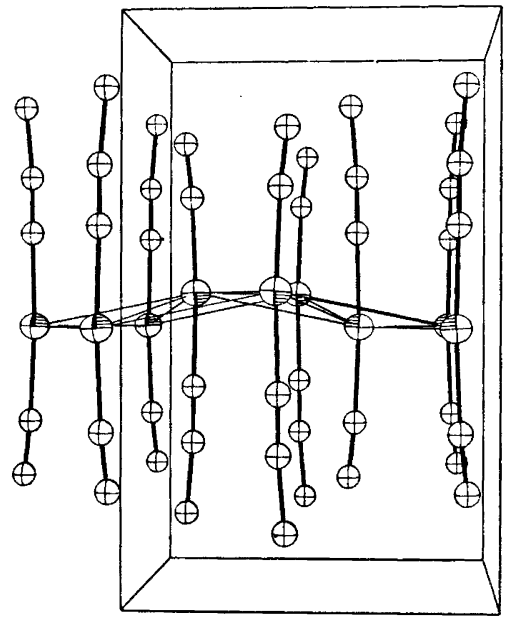

Fig. 2. A stereoscopic drawing showing the packing of molecules as seen along the $c$ axis. The $a$ axis is vertical and the $b$ axis is horisontal.

Acta Chem. Scand. A 30 (1976) No. 7 
higher bond order for $\mathrm{C} \cong \mathrm{N}$ in the complex than in the free isocyanide molecule. This is, however, not unusual when the metal is in an intermediate or high oxidation state. ${ }^{20} \mathrm{~A}$ slight increase $\left(c a .5-10 \mathrm{~cm}^{-1}\right)$ is caused by a kinematic coupling of the $\mathrm{M}-\mathrm{C}$ and $\mathrm{C}-\mathrm{N}$ oscillators. ${ }^{21}$ Of much more importance, however, is the effect of coordinating the isocyanide carbon to the positive metal ion. Coordination may be expected to increase the CN bond order and raising the frequency.

When an isocyanide coordinates to a transition element in a low oxidation state (mainly zero), the CN stretching frequency may be lower in the complex than in the free ligand..$^{20,22}$ This corresponds to a substantial transfer of electron density from the metal $d$-orbitals to suitable $\pi^{*}$ orbitals of the ligand. A metalcarbon $\pi$-bond thus established should result in a shorter $\mathrm{M}-\mathrm{C}$ distance and a longer $\mathrm{C}-\mathrm{N}$ distance. The former has been confirmed by $\mathrm{X}$-ray structure determinations. ${ }^{20}$

The present investigation does not support the idea of any appreciable amount of backdonation from the gold atom to the cyanide group either. The $\pi$-accepting tendency of $\mathrm{CN}^{-}$does not seem as high as for CNR which is of course reasonable in view of its negative charge..$^{23}$ It is reported, however, that in some cases the $\pi$-acidity of $\mathrm{CN}^{-}$and CNR are comparable. ${ }^{24}$

Acknowledgements. The author wants to thank cand. real. Jon Songstad, Department of Chemistry, University of Bergen, for a sample of crystals and Dr. N. W. Alcock, University of Warwick, England, for advice on computing matters. This investigation has been supported by a grant from The Royal Norwegian Council for Scientific and Industrial Research.

\section{REFERENCES}

1. Arai, G. Recl. Trav. Chim. Pays-Bas 81 (1962) 307.

2. Cotton, F. A. and Wilkinson, G. Advanced Inorganic Chemistry. A comprehensive text, 3rd Ed., pp. 903 and 1044.

3. Fischer, P. J., Taylor, N. E. and Harding, M. M. J. Chem. Soc. (1960) 2303.

4. Songstad, J. To be published.

5. Alcock, N. W. In Ahmed, F., Ed., The Analytical Method for Absorption Correction in Crystallographic Computing, Munksgaard, Copenhagen 1970.
6. International Tables for X-Ray Crystallography, Kynoch Press, Birmingham 1962, Vol. III, p. 204.

7. Cromer, D. T. Acta Crystallogr. 18 (1965) 17.

8. Corfield, P. W. R. and Shearer, H. M. M. Acta Crystallogr. 23 (1967) 156.

9. Rundle, R. E. J. Am. Chem. Soc. 76 (1954) 3101.

10. Ruben, H., Zalkin, A., Faltens, M. O. and Templeton, D. H. Inorg. Chem. 13 (1974) 1836.

11. Hesse, R. and Jennische, P. Acta Chem. Scand. 26 (1972) 3855.

12. Lawton, S. L., Rohrbaugh, W. J. and Kokotailo, G. T. Inorg. Chem. 11 (1972) 2227.

13. Dunitz, J. and Orgel, L. E. Adv. Inorg. Chem. Radiochem. 2 (1960) 34.

14. Charlton, J. S. and Nichols, D. I. J. Chem. Soc. $A(1970) 1484$.

15. Machmer, P., Read, M. and Cornil, $P$. C. R. Acad. Sci. Ser. B 262 (1966) 450.

16. Baker, R. W. and Pauling, P. J. J. Chem. Soc. Dalton Trans. (1972) 2264.

17. Rosenzweig, A. and Cromer, D. T. Acta Crystallogr. 12 (1959) 709.

18. Jones, L. H. and Penneman, R. A. J. Chem. Phys. 22 (1954) 965.

19. Stephany, R. W. Thesis, Utrecht 1973.

20. Bonati, F. and Minghetti, G. Inorg. Chim. Acta 9 (1974) 95.

21. Cotton, F. A. and Zingales, F. J. Am. Chem. Soc. 83 (1961) 351.

22. Bonati, F. and Minghetti, G. Gazz. Chim. Ital. 103. (1973) 373.

23. Ref. 2, pp. 721-722.

24. Sarapus, A. C. and Fenske, R. F. Inorg. Chem. 14 (1975) 247.

Received February 16, 1976. 